\title{
THE COMPOSITION OF HUMAN GALLBLADDER BILE AND ITS RELATIONSHIP TO CHOLELITHIASIS
}

\author{
By JOHN G. REINHOLD, L. KRAEER FERGUSON AND AMBROSE HUNSBERGER, JR. \\ (From the Biochemical Division, Laboratories and the Surgical Services, Philadelphia General Hospital; the Sur- \\ gical Outpatient Department, University of Pennsylvania Hospital; and the Department of Physiological \\ Chemistry, School of Medicine, University of Pennsylvania, Philadelphia)
}

(Received for publication December 17, 1936)

Chemical investigations of the activity of the gallbladder have aided notably in clarifying the etiology of gallstones. Detailed reviews have been published by Lichtwitz (1) and Ivy (45). Particularly important is the striking alteration of gallbladder function caused by infection of or injury to the mucosa demonstrated in the dog by the experiments of Drury, Rous and McMaster; Ravdin, Johnston and Riegel; and of Andrews and associates. It has been shown by these workers that changes in the composition of bile exposed to the action of pathologically altered gallbladders tended to diminish the effectiveness of the bile as a solvent for cholesterol. Thus, considerable experimental evidence has been presented to connect the development of gallstones with infection of or injury to the gallbladder mucosa. The most convincing support has been derived from experiments done upon dogs, although data have been published from the laboratories of Ravdin and of Andrews showing that similar processes appear to operate in the human gallbladder. Species differences, however, necessitate caution in drawing close analogy between observations made in the presence of experimental gallbladder injury of dogs and in human cholecystitis. As has been pointed out, human bile differs in composition from dog bile, and also, the response to disease and injury of the biliary tract in man is not quite the same as that of the dog under experimental conditions. Human bile is rich in cholesterol as compared with dog bile. It differs in type and amount of bile acid. Cholecystitis in the dog causes the gallbladder contents to become more alkaline, but in man the opposite effect is generally observed. Therefore, more complete investigation of additional human material is desirable to establish clearly the consequences of cholecystitis and its rôle in cholelithiasis, as well as to correlate more closely such observations with the studies on animals. The results of a chemical study of human gallbladder bile are reported in this paper. The explanation of gallstone formation provided by the work of Ravdin, Johnston, Riegel and associates and of Andrews, Schoenheimer and Hrdina is supported by our data.

\section{PROCEDURE}

Bile was aspirated directly from the gallbladder into a syringe by the surgeon in the course of operation. Precautions were taken to avoid exposure to air or loss of carbon dioxide. Preceding the operation, the usual saline enemas and morphine were given. Some of the patients received glucose intravenously in addition. Generally, the patients had fasted 12 to 15 hours before operation, occasionally somewhat longer.

Determinations of $\mathrm{pH}$ were completed within 1 to 2 hours after collection of the specimen. Other tests also were started with a minimum of delay. Occasional specimens could not be analysed promptly; $\mathrm{pH}$ determinations were then omitted. Analytical findings were not influenced appreciably by delays of several hours. The specimens were centrifuged and the precipitate, if any, examined for the presence of crystals or other formed elements. Measured amounts of centrifuged bile were added to warm absolute ethyl alcohol, heated to boiling, centrifuged, decanted, and the residue extracted twice with alcohol. The alcohol solution and washings were combined and diluted to volume in a volumetric flask. Aliquots were used for the determination of cholic acid, phosphorus and cholesterol. The absence of cholesterol esters from bile and the solvent action of the bile acids and phospholipid permit the use of alcohol alone as an extractive solvent for cholesterol. The latter was estimated by a modification of the Autenrieth and Funk method (2). Bile saponified two hours with 25 per cent potassium hydroxide was extracted with ether in a continuous extractor of the type described by Quick (3). Cholic acid was determined by the modification of the Gregory-Pascoe procedure developed by Reinhold and Wilson (4), using the precautions recommended for analysis of human bile. Turbidity resulting from the presence of desoxycholic acid was removed by addition of alcohol after color development as described in the method. Phospholipid values represent total phosphorus of the alcohol soluble components of bile. 
In the presence of bile acid salts alcohol appears to dissolve completely bile phospholipid, although Mathews (5) states that alcohol precipitates cephalin ordinarily. Analytical methods that are not specifically mentioned are those listed by Reinhold and Wilson (6). Bile was ashed preliminary to determination of cations. To avoid possibility of error due to the high concentration of solids, water was added to the sample taken for the chloride determination, as suggested by Sunderman and Williams (7). Analytical results have been calculated on the basis of the concentration per liter of bile.

Attempts to study changes in the bilirubin content of bile of diseased gallbladders were hampered by the difficulties of determining this substance quantitatively. When possible, direct comparison of the diluted bile with solutions of potassium bichromate was made. The latter were standardized with the aid of solutions of pure bilirubin $(0.025$ per cent potassium bichromate was equivalent to $0.38 \mathrm{mgm}$. per cent bilirubin). Obviously, the method was not applicable when oxidation of the bile pigment had occurred.

The specimens analysed were derived principally from pathological gallbladders showing evidence of inflammatory disease. In addition, specimens from gallbladders showing no distinct pathological changes, as well as specimens from gallbladders presenting cholesterosis or neoplastic disease, have been examined.

To demonstrate the cumulative nature of the pathological changes in cholecystitis, data are arranged in Tables I to III according to the absence or presence and the severity of cholecystitis. Table I includes data for a group of control specimens. In Tables II and III are shown figures for specimens taken from gallbladders exhibiting moderate or marked evidence of disease, respectively. When possible, classification has been made upon histological evidence. When the gallbladder was not removed or examined, the conclusions of the surgeon concerning the condition of the gallbladder were accepted. Histologically, thickening of the walls, extent of fibrosis, number and quality of villi, and presence and degree of inflammatory reaction and cellular infiltration have been given the most weight. Tabulated according to these criteria, fair homogeneity is observed in each group, while significant differences between the groups likewise become apparent. An alternative grouping, employed in an earlier study (Reinhold and Ferguson (8)) and considered in connection with the classification of the present material, depended on the presence of calculi in the gallbladder or of both calculi and obstruction. Actually, the difference in distribution of specimens according to the two plans was not great, since only 5 of 35 gallbladders showing evidence of inflammatory changes were without calculi, and only 2 failed to show crystals of cholesterol.

The calculi encountered were almost all of the cholesterol calcium pigment type or of the cholesterol type. It was not always possible for the authors to examine the stones removed. The analytical findings of Ray (9) and of Riegel, Ravdin, Johnston and Morrison (47) indicate that there is less difference in composition between various types of calculi than had been supposed.

\section{Composition of bile from gallbladders normal in appearance}

Table I includes observations made upon bile from gallbladders without perceptible pathological lesions or with slight changes. Laparotomy was undertaken either for exploration or because of disease not involving the biliary tract, although gallbladder disease was suspected in several patients due to the association of certain characteristic symptoms with failure to visualize the gallbladder by the cholecystographic technic of Kirklin (51). The group is heterogeneous, and there exists a distinct possibility that abnormalities of bile secretion and of gallbladder function influenced the composition of some specimens. Bile from normal living individuals, however, is rarely available. The specimens have been arranged according to cholate concentrations in descending order, since it is reasonably certain that ability to concentrate bile salts is an especially significant indicator of functional capacity. Thus, specimens in the upper half of the table are most nearly normal. It is evident that figures for some specimens in the lower portion overlap data for specimens from patients suffering from cholecystic diseases. Graham and Mackey (50) have pointed out difficulties of confirming at times by histological methods the presence of gallbladder abnormalities. It is possible or even probable that gallbladder disease existed unrecognized in this group. Adhesions involving the gallbladder existed in 6 patients. Crystals, either of choles- 


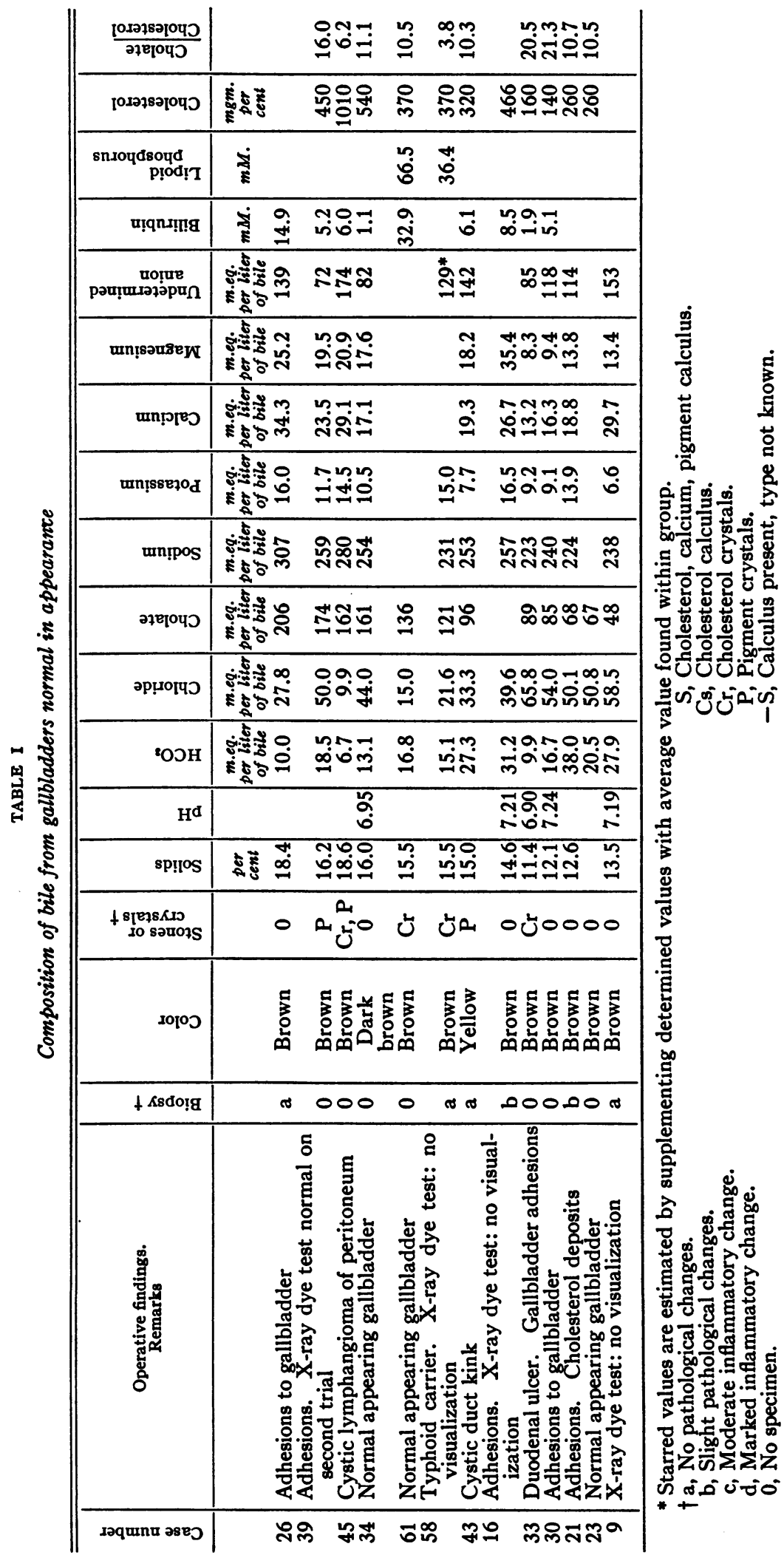


JOHN G. REINHOLD, L. KRAEER FERGUSON AND AMBROSE HUNSBERGER, JR.

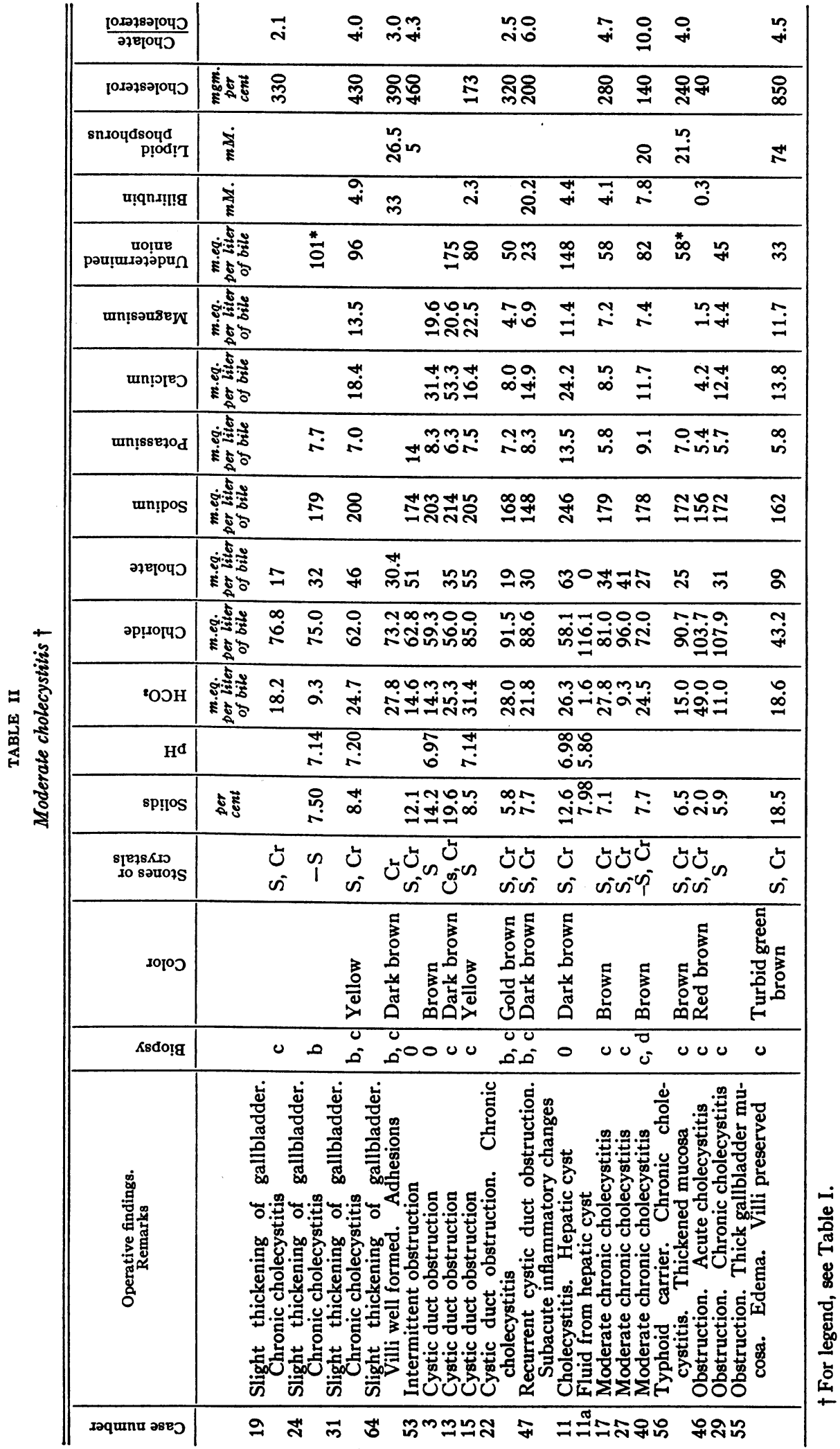




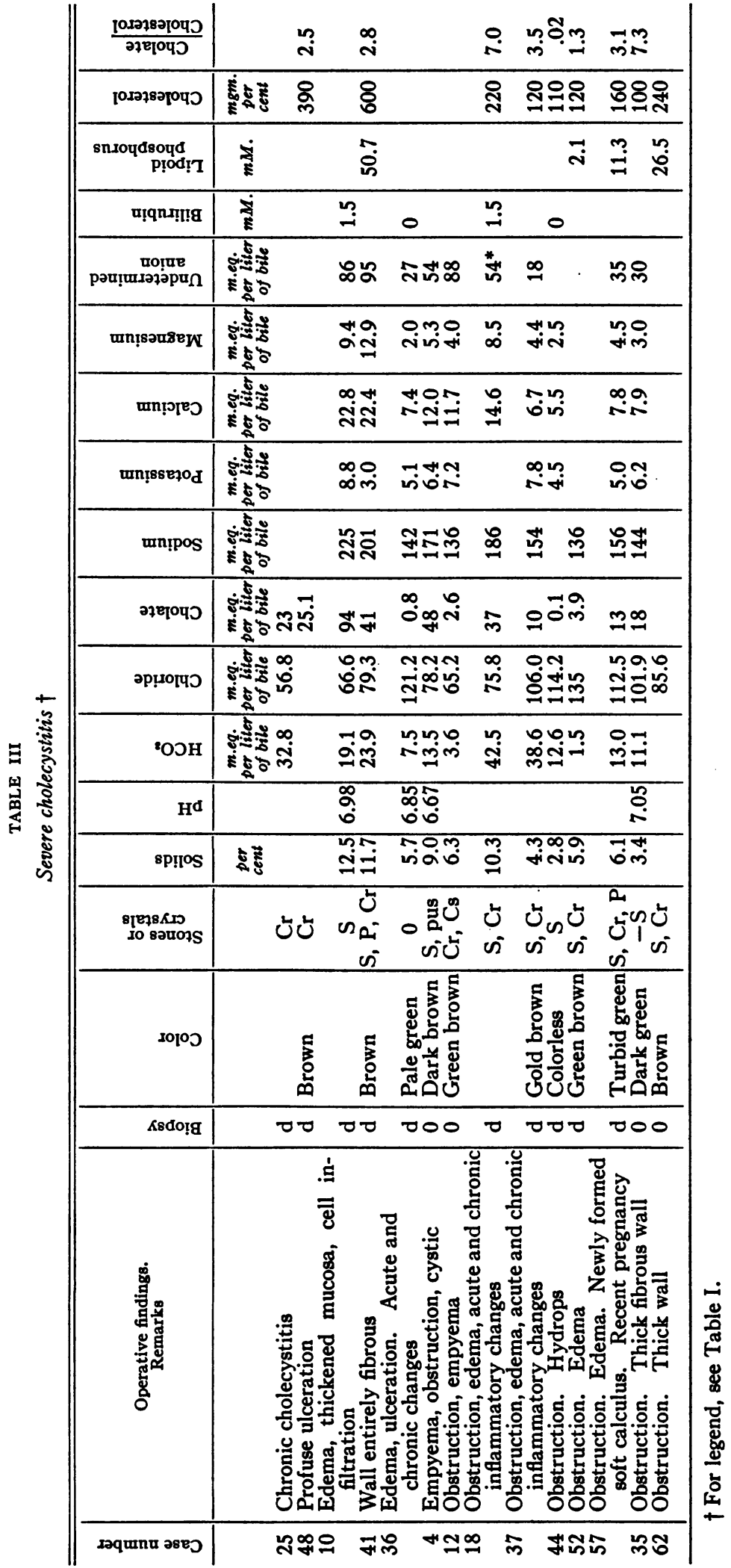


terol or bile pigment, were found in 5 specimens, although always in small numbers. Neither crystals, adhesions, nor failure of visualization by $\mathrm{x}$-ray, could be correlated with distinctive changes in composition of the bile specimens. However, Johnston et al. (10), and Riegel and coworkers (47), by repeated testing, frequently with larger amounts of dye, have succeeded in demonstrating chemical differences between specimens secured from gallbladders exhibiting normal response to cholecystography from those without calculi that failed to do so. The specimens ranking near the top in Table I varied only slightly in regard to calcium, chloride and bile salt concentrations from two samples of normal human gallbladder bile analysed for these constituents by Johnston, Ravdin, Riegel and Allison (10). Concentrations of bile acids in those specimens we consider most nearly normal (the first 7 in Table I) range far above all except two values reported by Andrews (11) for "normal" gallbladder bile. It is doubtful whether any of the specimens labeled normal by this author should actually be so considered.

All specimens listed in Table I contained high concentrations of solid material. This is largely bile acid and phospholipid, if the two figures for the latter may be considered representative. Determined bile acid, glycocholate and taurocholate, often accounted for more than half the total solids. The high concentrations of these substances are to be contrasted with the far lower concentrations found when the gallbladder mucosa is perceptibly injured. Owing to the fact that the modified Pettenkofer reaction employed for the determination of bile acids is specific for the cholic acids (Reinhold and Wilson (4)), other bile acids that occur in human bile are included in the undetermined anion. ${ }^{1}$ Desoxycholic acid appears to be most important quantitatively, according to Wieland and Reverey (12) and Doubilet (13). Chenodesoxycholic acid (12) and lithocholic acid (14) have been isolated from human bile and from gallstones, although data are not available relative to their concentration. It is to

\footnotetext{
1 Doubilet (13) has justly pointed out that data for human bile based upon this method alone are incomplete. In the present study this objection is avoided because changes in the undetermined anion offer means for detecting gross changes in other bile acids.
}

be expected that differences between normal and pathological specimens resembling those seen for the cholic acids exist also for the undetermined bile acids. High figures for undetermined anion in the normal and moderately pathological specimens do indeed support this conclusion although the contrast is not as clearly defined. That there is a change in the character of bile acids secreted under certain abnormal conditions is suggested by the work of Greene, Walters and Fredrickson (15), of Ravdin, Johnston, Riegel and Wright (16), and of Breusch and Johnston (17). Doubilet (13) recently has demonstrated such a qualitative alteration. Doubtless the high undetermined anion concentration, frequently observed in our series in conjunction with relatively low cholate, is the result of a similar change in the type of bile acid secreted by the liver.

Chloride concentrations in specimens from gallbladders without demonstrable pathological changes were considerably less than the concentrations of organic anions. The relatively low chloride figures may be contrasted with the high values observed in pathological material described in the next section. Similar differences have been observed by Johnston et al. (10). The concentration of chloride varies inversely with that of bile acid and compensates changes in the latter. Bicarbonate undergoes somewhat similar alterations, and it also may replace or be replaced by bile acid. Bicarbonate rarely exceeds chloride in concentration and ordinarily it is considerably less. While high bicarbonate has occasionally been found associated with diminished chloride concentrations, generally both are increased or lowered together.

The concentration of cation in bile likewise is governed to a considerable extent by the level of bile acid; consequently, sodium and other cations as well are relatively high in the specimens of this group. Sodium is by far the most important of the cations so far as concentration is concerned, with calcium, magnesium and potassium ranking in the order mentioned when considered in terms of milli-equivalents per liter. Magnesium concentrations in bile frequently outweigh those of calcium in contrast to serum where magnesium approximates only one-half of the calcium concentration. Furthermore, the divalent cations 
of bile constitute a considerably larger fraction of the total base than in serum. Concentrations of all cations of bile normally exceed by considerable amounts the concentrations in serum, while the total cation concentration is consistently above 250 m.eq. per liter of water as compared with the average concentration in serum of $167 \mathrm{~m}$.eq. Despite this discrepancy, it has been demonstrated repeatedly that bile and serum are iso-osmotic (see Brand (48), Strauss (49), Ravdin, Johnston, Riegel and Wright (16), and Gilman and Cowgill (18)). The anomaly is a manifestation of the abnormal behavior of ions of low molecular weight in the presence of large ions. Hammarsten (19) has observed that in the presence of bile acids, as well as of other compounds of high molecular weight, osmotic activities of smaller ions are diminished.

The reaction of bile from gallbladders showing no evidence of disease was found in an earlier investigation by two of the writers (Reinhold and Ferguson (8)) to vary between $\mathrm{pH} 7.10$ and 7.30. Although it was suggested that greater variation was to be expected, in the present series 3 of 5 similar specimens fell within these limits. The 2 remaining specimens were somewhat more acid in reaction, the $\mathrm{pH}$ being 6.90 and 6.95 . The range of values for specimens of this class must be broadened to include the latter. Low $\mathrm{pH}$ was associated with low concentrations of bicarbonate.

Comparison of $\mathrm{pH}$ values reported for dog and human bile shows that gallbladder bile of dogs has been found to be somewhat more acid in reaction (Okada (20) ; Drury, McMaster and Rous (21); unpublished observations of the writers) than human gallbladder bile (Drury, McMaster and Rous (21); Reinhold and Ferguson (8); Andrews (11)). Undoubtedly, differences in the nature and concentration of the species-predominant bile acids are responsible. Human bile contains principally the relatively weak glycine-conjugated cholic and desoxycholic acids. Bile acid of the dog, on the other hand, consists primarily of the strong taurine-conjugated cholic acid. It has been shown that the $\mathrm{pH}$ of dog bile is governed by the concentration of taurocholic acid (Reinhold and Wilson (6)). In human bile, because of the relatively weak character of the bile acids, such a relationship is not clearly dem- onstrated. Interpretation of the rôle of bile acid in the regulation of the reaction of human bile is complicated by the appreciable concentration of such acids included in the undetermined anion.

Carbon dioxide tensions of gallbladder bile frequently are very high. Calculation was made from the data for $\mathrm{pH}$ and carbon dioxide concentration by the Henderson-Hasselbalch equation according to Peters and Van Slyke (22). Values of the same magnitude have been established for urine by Sendroy, Seelig and Van Slyke (23), while contents of intestinal loops also may have high carbon dioxide tensions according to deBeer, Johnston and Wilson (24). It would appear that carbon dioxide tensions of secretions may differ appreciably from those of blood.

In normal bile, total cation concentrations consistently exceed the concentrations of total determined anion. The undetermined anion, as already indicated, is made up chiefly of bile acids other than cholic acid, although certain phospholipids may bind a portion of the base represented in this fraction. Inorganic phosphorus, if present, exists in amounts insignificant by comparison with other anions. None was found in dog bile (Reinhold and Wilson (6)). The presence of appreciable concentrations of inorganic phosphorus in bile has been reported; however, this may have originated by hydrolysis of phospholipid. Riegel et al. (47) found little phosphate in human biliary calculi.

Aronsohn and Andrews (25) have attempted to explain the acidification of bile in the gallbladder as a consequence of increased concentration of phosphorus and protein. Their conclusion, based on an increase in total phosphorus in gallbladder bile as compared with fistula bile, is not valid since the total phosphorus consists almost entirely of phospholipid. The latter, according to Hammarsten (26), is chiefly lecithin. As lecithin does not exert appreciably acidic properties at the $\mathrm{pH}$ of gallbladder bile (Fischgold and Chain (27) ; Chain and Kemp (28) ; Jukes (29)), it is not permissible to assign to the phosphorus of bile the acidifying action observed. Likewise, it appears improbable that bile protein would possess the powerful acidifying action implied by Aronsohn and Andrews. As already noted, there 
is considerable evidence showing that bile acid concentration is the chief factor regulating the $\mathrm{pH}$ of bile, and that acidification of gallbladder bile is primarily a result of the large increase in bile acid concentration as hepatic bile is concentrated in the normal gallbladder.

Cholesterol in these specimens from gallbladders without pathological changes varied in concentration between 140 and $1010 \mathrm{mgm}$. per cent. The highest value cited was also the highest in the entire series. The patient suffered from cystic lymphangioma of the peritoneum. Despite the elevated concentration of bile acids, cholesterol crystals were detected in this specimen. Also, in two other specimens where cholesterol concentrations were not elevated, a few cholesterol crystals were seen although bile acid concentrations were high. It must be conceded, however, that crystals could not be found in the abundance that is ordinarily characteristic of bile from pathological gallbladders. The importance of the ratio between bile acid and cholesterol as a factor governing the solubility of cholesterol has been stressed by Newman (30), Andrews, Schoenheimer and Hrdina (31), and Johnston et al. (10). Such a relationship between cholate and cholesterol may be seen in the present series. It is noteworthy that only two specimens of this normal group had a cholate: cholesterol ratio of less than 10. The high undetermined anion of these non-conforming specimens suggests that the ratio of total bile acid to cholesterol would be considerably higher. ${ }^{2}$

\footnotetext{
2 Other substances in bile beside cholesterol may react to give color with the Liebermann-Burchard reagents. Thus Wright (32) found the colorimetrically determined values for cholesterol in dog bile to be higher by 20 per cent than the results of determination by digitonin precipitation. Wieland and Reverey (12) report that anthropodesoxycholic acid gives a weak LiebermannBurchard reaction. While the term cholesterol has been used in the text and tables, it should be regarded as an expression of total non-saponifiable material giving the Liebermann-Burchard reaction. For the purposes of the present paper, there is reason to believe that the "cholesterol" values approximate cholesterol concentrations without gross inaccuracy. Comparisons with gravimetric digitonin determinations showed that colorimetric estimations did not vary more than 10 per cent from the digitonin values.
}

\section{The composition of bile from diseased gallbladders}

Distinct changes from the normal composition of bile accompanied even slight pathological alterations of the gallbladder mucosa. The effects of cholecystitis of mild or moderate degree are shown in Table II. Gallstones were present in 16 of the 18 gallbladders from which these specimens were removed, while all of the bile specimens contained cholesterol crystals. Obstruction of the cystic duct was found at operation in 9 of the patients represented in this group.

Severe cholecystitis, with widespread changes in the mucosa, caused alterations in the composition of the contents of the gallbladders similar to those observed in moderate gallbladder disease, though far more pronounced. Data for 15 specimens of this character are presented in Table III. Here, likewise, the incidence of calculi was high. However, two specimens contained no crystals, nor were calculi found in the gallbladders. Partial or complete occlusion of the bile ducts caused by calculi existed in 10 of the 14 patients. Changes from the normal were most marked in the presence of obstruction. The group was far from homogeneous in respect to appearance of the specimens, which varied from essentially normal pigmentation to practically pigment-free "white bile."

The lowered concentration of total solids to be seen even in the presence of moderate injury to the gallbladder (Table II) reflects a marked impairment of the ability to retain and concentrate material reaching the gallbladder in the hepatic bile. Severe damage to the gallbladder mucosa depressed the solids content of the bile to a greater extent (Table III). Particularly striking changes were associated with obstruction of the cystic and common bile ducts. Estimation of the protein contained in certain of these specimens showed increased concentrations in both groups as compared with normal specimens. Thus the loss of ability to concentrate bile as measured by determinations of total solids is obscured to some extent by elevated protein, and was greater than the figures for total solids would indicate.

Striking reductions in concentration of bile acids in bile in the presence of gallbladder disease have been reported $(10,11,30,31,47)$. Our 
analyses likewise showed that cholic acid concentrations were lowered consistently in specimens comprising this group. The loss of bile acid explains the major portion of the decrease in solids. Whereas cholate in normal specimens exceeds 150 m.eq. per liter, the average concentration in the presence of gallbladder disease was reduced to 34 m.eq. per liter (Table II). Under similar conditions, undetermined anion concentrations were generally below the normal level although not as much so as cholate. It seems probable that undetermined bile acids behaved not unlike the cholic acids. Even lower concentrations of bile acids were observed in bile from badly diseased gallbladders (Table III), and in a few specimens, particularly in the presence of obstruction and empyema, only traces of cholate the gallbladder, equivalent quantities of inorganic anions, largely chloride, replace the organic electrolyte so lost. Excessive concentrations of chloride are observed in the presence of marked edema of the gallbladder mucosa when the chloride concentration of the contents often exceeds that of serum. Riegel, Ravdin, Johnston and Morrison (33) have reported high chloride concentration in hydrops fluid. The importance of increased chloride as an indicator of gallbladder dysfunction has been stressed by these workers (10).

Bicarbonate, like chloride, may replace bile acid that diffuses from the injured gallbladder. In certain of the specimens represented in Tables II, III, IV and V, bicarbonate is increased in comparison with the normal while a few genuinely high values are seen. However, in the most

TABLE IV

Cholesterosis $\dagger$

\begin{tabular}{|c|c|c|c|c|c|c|c|c|c|c|c|c|c|c|c|c|c|}
\hline 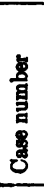 & $\begin{array}{l}\text { Operative findings. } \\
\text { Remarks }\end{array}$ & 容 & 。융 & 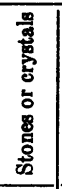 & 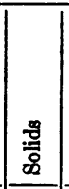 & 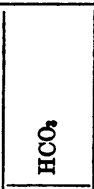 & 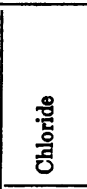 & 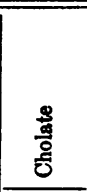 & 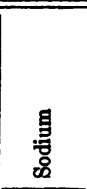 & $\begin{array}{l}\text { 量 } \\
\text { 总 } \\
\text { م }\end{array}$ & 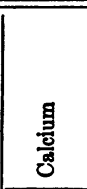 & 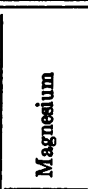 & 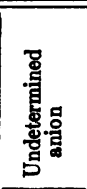 & 善 & 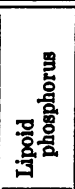 & 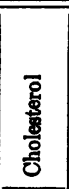 & : \\
\hline $\begin{array}{l}49 \\
28 \\
54\end{array}$ & $\begin{array}{l}\text { Cholesterosis } \\
\text { Cholesterosis } \\
\text { Cholesterosis. Gangre- } \\
\text { nous pancreatitis }\end{array}$ & $\begin{array}{l}b_{1}, c \\
c \\
c\end{array}$ & Yellow & $\begin{array}{c}\mathrm{C}_{\mathrm{s}} \\
\mathrm{Cr} \\
\mathrm{s}, \mathrm{Cr}\end{array}$ & $\begin{array}{c}\text { per } \\
\text { cent } \\
\\
8.1 \\
12.2\end{array}$ & \begin{tabular}{|c|} 
mereq. \\
per liter \\
of file \\
63.1 \\
22.3 \\
15.1 \\
\end{tabular} & \begin{tabular}{|c|} 
meeg \\
per liter \\
of bile \\
32.1 \\
82 \\
38.6
\end{tabular} & \begin{tabular}{|c|} 
mequ. \\
per liter \\
of bile \\
23 \\
23 \\
36 \\
76
\end{tabular} & $\begin{array}{c}\begin{array}{c}\text { m.eq. } \\
\text { per liter } \\
\text { of bile }\end{array} \\
177 \\
137\end{array}$ & 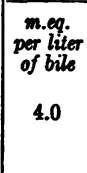 & 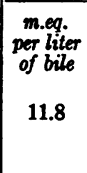 & 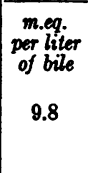 & $\begin{array}{c}\begin{array}{c}\text { m.eq. } \\
\text { per lier } \\
\text { of bile }\end{array} \\
61\end{array}$ & \begin{tabular}{|c|}
$m M$ \\
3.9
\end{tabular} & $\begin{array}{c}m M . \\
9.3\end{array}$ & $\begin{array}{c}\text { mom. } \\
\text { per } \\
\text { cent } \\
240 \\
192 \\
192\end{array}$ & $\begin{array}{r}3.8 \\
16.1\end{array}$ \\
\hline
\end{tabular}

† For legend, see Table I.

could be detected while other bile acids likewise appeared to have vanished. Heightened permeability of the gallbladder mucosa which ceases to act as a barrier to bile salts and perhaps to other substances of high molecular weight undoubtedly is foremost among the factors leading to such changes. There is little doubt that the lowered concentration of bile acid diminishes the solvent action of the bile for lipids, and leads in turn to crystallization of cholesterol.

High chloride concentrations were associated consistently with the low bile acid concentrations typical of cholecystitis. Normally, as the concentration of bile acid increases, chloride diffuses from the gallbladder, thus maintaining osmotic equilibrium. However, in the presence of moderate cholecystitis the relatively high concentration of chloride present in hepatic bile not only remains undiminished, but, as bile acid diffuses from severely damaged gallbladders bicarbonate is more often decreased. It appears that the abundant secretion of bicarbonate in the dog described by Ravdin, Johnston, Austin and Riegel (34) as a consequence of injury to the mucosa is not the prevailing response to chronic cholecystitis in the human. Perhaps it represents an early phase in the response to injury, although the occurrence of calculi composed of calcium carbonate implies a persisting increase in bile $\mathrm{pH}$.

Although but little change in $\mathrm{pH}$ of bile accompanies moderate gallbladder disease, a shift toward more acid reactions commonly is associated with marked injury to the walls of this organ. In this respect, data obtained in the present study confirm the earlier observations of the writers.

Decreased $\mathrm{pH}$ and bicarbonate under these circumstances provide an interesting contrast to the 


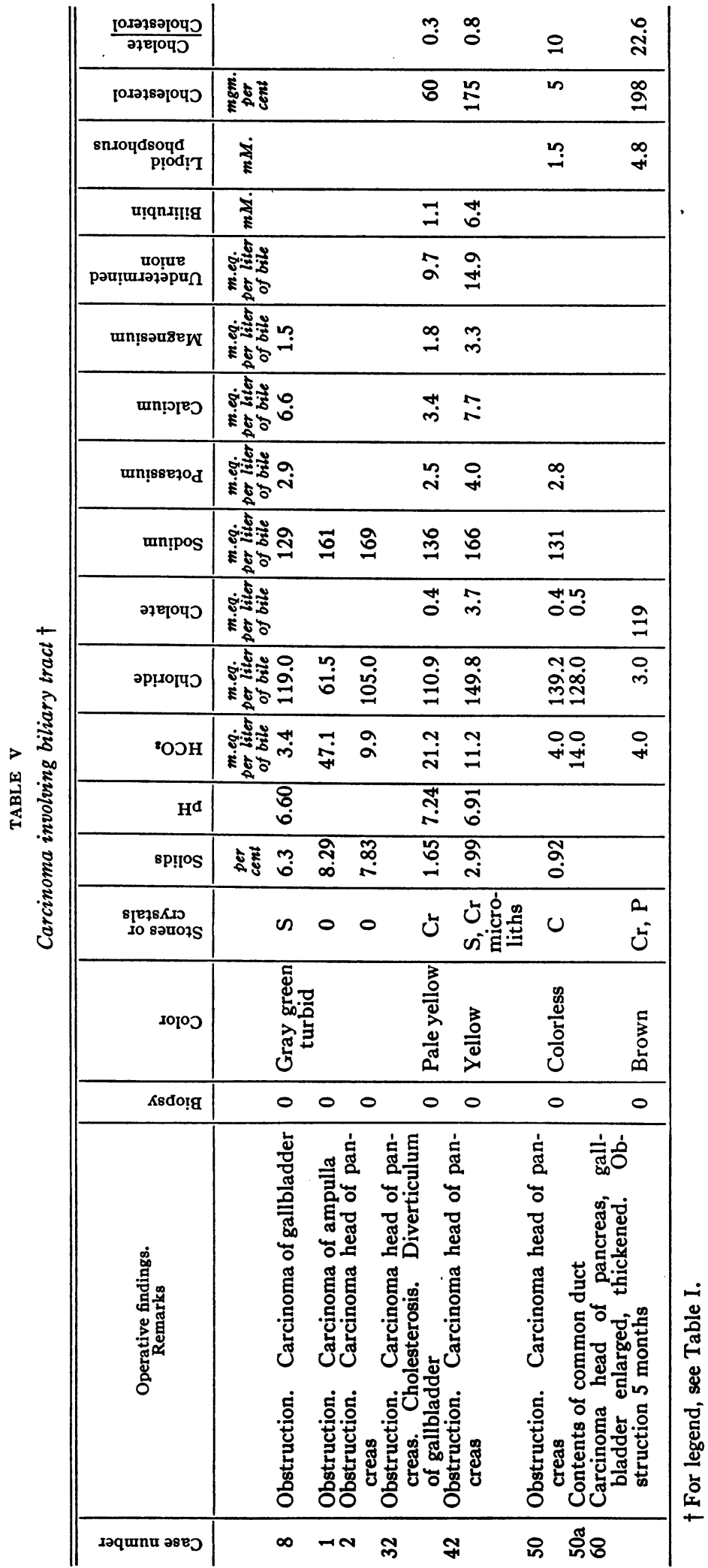


changes observed in the gallbladder bile of dogs following the development of cholecystitis. Drury, McMaster and Rous (21), and Johnston et al. (10) have shown that injury to the mucosa of the gallbladder causes the $\mathrm{pH}$ and bicarbonate of dog's gallbladder bile to increase. Again, the differences in the chemical properties of the predominating bile acids in human and dog bile aid in explaining the inconsistency. Salts of the weakly acidic glycine-conjugated acids of human bile on undergoing hydrolysis would impart a slightly alkaline reaction to solutions. As already mentioned, the slightly alkaline reaction of normal human gallbladder bile is a consequence of this property. On the other hand, when glycocholic acid diffuses from the diseased gallbladder and is replaced principally by chloride, the reaction will tend to become less alkaline. In contrast, the strong taurine-conjugated bile acids of dog bile normally displace practically all of the bicarbonate (and chloride) as concentration proceeds in the gallbladder so that ordinarily the reaction is distinctly acid. Under these circumstances loss of bile acid from the gallbladder of the dog in the presence of cholecystitis, particularly if accompanied by secretion of bicarbonate (see Ravdin et al. (34)), will cause the marked increase in bile $\mathrm{pH}$ observed in this species. Impaired buffering capacity facilitates changes in reaction that occur in injured gallbladders.

The lowered $\mathrm{pH}$ of the contents of severely damaged gallbladders indicates that acidic constituents are present in significant concentrations. These are not cholic acids, free or conjugated, since low cholate is found in this class of specimens. Appreciable amounts of undetermined anion are observed. Its identity has not been established. That it is not phospholipid is shown by simultaneous occurrence of very low bicarbonate with the smallest phospholipid concentrations of the entire series.

Diffusion of bile acid out of the diseased gallbladder is only partially compensated by the rise in chloride (with or without a rise of bicarbonate). There is invariably a simultaneous and roughly proportional decrease in concentration of total base. While quantitatively smaller than the alteration of the chloride, it is nevertheless of sufficient size to bring about marked reduction of the total cation concentration of the pathological specimens, as well as that of individual cations. Sodium, being the principal cation, accounts for the major portion of the change. However, calcium concentrations do not change to the same extent as a concentration of other cations.

The presence of considerable amounts of calcium as a constituent of many gallstones arouses interest in the concentration of this ion in bile of diseased gallbladders. Marked irregularity is shown in the response of calcium concentration of bile to gallbladder disease. Alterations that have been observed are most frequently in the direction of lower values. Occasional high concentrations were found in the contents of certain badly diseased gallbladders. Calcium concentration in normal bile varies directly as the concentration of bile acids, and no doubt a relationship exists analogous to that between serum calcium and serum protein. Thus high concentrations of bile acid would exert a protective action tending to keep calcium in solution by diminishing ionization. On the contrary, low bile acid levels would favor precipitation of calcium, thus contributing to a widespread occurrence of calcium in calculi. Inouye and Ryuichi (35) found that sodium taurocholate prevented precipitation of calcium although glycocholate was ineffective.

In disease, the changes in bile calcium are complex. Quite probably high calcium concentrations in the presence of severe cholecystitis are to be attributed to exudation or transudation. This explanation is supported by the simultaneous increase in the protein of the bile shown by unpublished observations of the writers. Riegel et al. (33) refer to the process by which calcium is increased as secretion. Phemister, Day and Hastings (36) have presented interesting examples of extreme accumulation of calcium in the gallbladder.

In cholecystitis, concentrations of bile magnesium are diminished. The calcium-magnesium ratio of the gallbladder contents ordinarily is lowered in comparison with that observed in normal specimens, approaching more nearly the ratio that characterizes blood serum or transudates. Potassium, like sodium, also approaches values commonly found in serum.

Contrary to expectations, cholesterol concen- 
trations are lower in our specimens from pathological gallbladders, as judged by averages, than in the normal material. Differences become greater as the severity of injury to the mucosa increases, until the average cholesterol of Group IV (marked cholecystitis) is about half that of the normal. Between these extremes fall the averages of the intermediate groups. Individual variations within all groups are large. The low figures undoubtedly reflect a decreased capacity of the bile for holding cholesterol in solution.

These results are in agreement with those of Newman (30), Spanner and Bauman (37), Andrews et al. (31) and Riegel et al. (47) in showing that the underlying cause of the crystallization of cholesterol is not a primary excess of this substance, but rather a defect of the solvent. The obvious lowering in the ratio of cholic acid to cholesterol in pathological specimens, as compared with normals, provides a quantitative measure of this change. Our ratios are lower than those of certain other workers who employed the less specific determination of hydrolyzed amino-nitrogen for analysis of bile acids. In general, however, the results are similar. Despite the high cholesterol concentrations of many normal specimens, crystals of cholesterol were seldom encountered in such specimens. On the other hand, it appears that crystals and calculi rarely are absent from the contents of diseased gallbladders and usually are present in great abundance despite the lowered concentration of dissolved cholesterol.

Bilirubin solubility, like that of cholesterol, must depend upon the lipid-bile acid relationship since gallbladder bile usually lacks the alkalinity requisite to maintain bilirubin in aqueous solution. Furthermore, the activity of calcium undoubtedly increases as bile acid concentrations decrease. Thus loss of bile acid and lipid with the further likelihood of an increase in calcium concentration and activity may readily bring about precipitation of bilirubin. Possibly, because of the limitations of the method, it has not been possible to relate the occurrence of gallstones with the incidence of either high or low concentrations of bilirubin. The concentration of bilirubin in bile, as determined by the procedure described, varied widely both in the normal and in the several groups of pathological specimens. However, low concen- trations were characteristic of the specimens from the most severely damaged gallbladders, as one might expect on the basis of physical factors. Not infrequently, crystals of bile pigment, the so-called calcium-bilirubin crystals, were present in specimens of all groups. Their presence appeared to be independent of concentration of bilirubin, calcium or hydrogen ions. The close correlation with the occurrence of cholecystitis that was found to exist in the case of cholesterol crystals was not observed.

The investigations of Fürth and Scholl (38) have again demonstrated the importance of phospholipid in the presence of bile acid as a solvent for cholesterol. Since bile is rich in lecithin and perhaps other phospholipids as well, these substances undoubtedly exert an important influence on the properties of bile as a solvent. An attempt has been made to determine the approximate concentration of phospholipid in the various specimens for the purpose of discovering whether cholecystitis led to any significant alterations in these substances. It appears that, like cholesterol, lipid phosphorus tends to remain in the damaged gallbladder while bile acid diffuses away. However, being comparatively unstable and perhaps more readily soluble than cholesterol, these substances would not persist as concretions as cholesterol does.

Protection of the gallbladder against the deleterious effects of bile salts is undoubtedly an important function of the lipids of bile. An injurious action of aqueous bile acid solutions on the gallbladder mucosa has been described by Riegel, Ravdin and Johnston (39), and Aronsohn and Andrews (25). Riegel and associates have also described a protective action of cholesterol against bile salts, while Ishii (40) also has found a similar protective action of phospholipid against bile salts.

Cholesterosis. No characteristic chemical composition of bile could be related to the presence of cholesterosis (strawberry gallbladder). While changes from the normal exist (Table IV), these were in general similar to those observed in cholecystitis of corresponding severity. The bile cholesterol was not elevated.

Neoplasm. The composition of the contents of the gallbladder in the presence of malignant 
growths involving the biliary tract is shown in Table V. Obstruction of the cystic or common bile ducts existed as well in all of these patients. Despite the absence in most cases of conspicuous gross or microscopic changes in the gallbladder, the composition of its contents was profoundly altered. Such a finding suggests that obstruction may alter the composition as well as the secretion of bile. It is known that suppression of bile secretion follows obstruction of the common bile duct. Contrasting with the remainder of the group is Specimen 60, where malignancy and obstruction of possibly as long as 5 months' duration had no effect other than marked inspissation of the bile.

Hepatic cyst. An hepatic cyst was encountered in Patient 11. Fluid was aspirated from the cyst, and, after removal of leukocytes by centrifugation, was analysed by the methods used for bile. The specimen was colorless but distinctly opalescent. Cultures were negative. The specimen contained 7.89 per cent solids, 118.1 m.eq. per liter chloride, 1.6 m.eq. bicarbonate; the $\mathrm{pH}$ was 5.86. The resemblance of these figures to those found for the contents of severely damaged gallbladders is at once evident.

\section{DISCUSSION}

Diminished concentration of bile acid, as typified by cholic acid, proves to be an almost invariable accompaniment of injury to the gallbladder mucosa. This close association provides evidence of increased permeability of the wall of the gallbladder to bile acid, while loss by diffusion best explains the low bile acid concentrations. However, in the presence of injury to the hepatic parenchyma (Doubilet (13); Andrews, Hrdina and Dostal (41)), in pregnancy (Riegel, Ravdin, Morrison and Potter (42)) or obstruction of the bile ducts (Goff, Hrdina and Andrews (43); McMaster, Broun and Rous (44); Greene, Walters and Fredrickson (15)), alteration or suppression of bile acid secretion may be additional factors. Cholesterol and, presumably, phospholipid, fail to diffuse from the damaged gallbladder as does bile acid. The failure of phospholipid to form deposits like those of cholesterol may be explained by differences in stability and solubility. The evidence provided by Andrews, Schoen- heimer, and Hrdina (31) and by Ravdin, Riegel, Johnston, and Morrison (52) to explain formation of calculi in the gallbladder receives additional confirmation from our data.

Other changes in chemical composition of bile in cholecystitis may in a large measure be referred to a primary loss of bile acid. Chloride or, less frequently, bicarbonate replaces the anion lost by diffusion of bile acid from the gallbladder. Thus the concentrations of these ions are increased. Diminished total solids and decreased concentration of total base likewise are directly related to the decline in bile acid concentration.

An end result of changes that occur in the contents of the gallbladder with an inert or abnormally functioning mucosa is replacement of the hydrolyzed salts of weak acids, i.e., sodium glycocholate and glycodesoxycholate, by sodium chloride, with a shift of $\mathrm{pH}$ from the slightly alkaline reaction normally observed toward more acid reactions. The distinctly acid reactions of many specimens from badly damaged gallbladders are unexplained, however, although loss of buffering capacity facilitates the change. Increased alkalinity, at times observed, results from secretion of bicarbonate under similar circumstances. Weiser and Gray (46) and others suggest as one mechanism for gallstone formation, a shift in $\mathrm{pH}$ from alkaline to acid with resultant precipitation of cholate. Actually, bile acid concentration governs the $\mathrm{pH}$ of bile. It is our belief that changes in $\mathrm{pH}$ are incidental to more fundamental changes in the constitution of bile, and that change of $\mathrm{pH}$ is of secondary importance as a causative factor in formation of cholesterol or mixed stones. Despite the primary rôle in cholelithiasis assigned to changes in $\mathrm{pH}$ by many workers, no suggestion has been offered by them as to how the hypothetical change in the reaction of bile giving rise to gallstone formation is to be brought about. Because of the acid reaction of many specimens of gallbladder bile, it is quite unlikely that soaps are present in significant amounts.

Calcium usually is lowered in the contents of diseased gallbladders, although this response to injury is variable. Ocasional noteworthy exceptions with striking increases have been observed. While commonly lowered in comparison with val- 
ues found in normal specimens, calcium concentrations remain higher than those of blood serum. It is significant that the concentration of bile calcium is lowered less in proportion to the normal than is the concentration of bile acid. Since bile acids undoubtedly aid in maintaining calcium (and bilirubin) in solution, the ubiquitous occurrence of calcium in gallstones would follow as a result of this altered relationship between bile acids and calcium. An additional factor that may favor precipitation of calcium is secretion of bicarbonate by the gallbladder. Although a typical response in dogs, our data suggest that it is infrequently encountered in humans. The behavior of magnesium differs from that of calcium, and magnesium concentrations are not maintained at high levels in the presence of gallbladder disease.

Sterile fluid found in an hepatic cyst closely resembled in composition the fluid collected from gallbladders where obliteration of functioning mucosa or complete long-standing obstruction of bile ducts had rendered the organ incapable of function.

Cholesterol crystals in the gallbladder contents quite consistently accompanied cholecystitis. The detection of such crystals in specimens of bile therefore provides good evidence for the existence of cholecystitis. Such evidence is not necessarily conclusive for occasionally crystals are found in the absence of pathological changes of the gallbladder. However, our data support the application of this test for diagnosis of cholecystitis, provided representative samples of gallbladder bile are secured for examination. A close correlation existing between the ratio of cholic acid to cholesterol and the incidence of cholesterol crystals or concretions reported by previous workers has been confirmed.

\section{SUMMARY}

Severe cholecystitis brings about serious defects in gallbladder physiology that result in marked alteration in chemical composition of gallbladder bile. Changes that have been observed in the presence of gallbladder disease are sufficiently marked (qualitatively and quantitatively) to lead to calculus formation. Cholesterol varies widely in concentration in the control specimens as well as in those specimens from pathological gallbladders. Low values for cholesterol were found in the presence of obstruction of the bile ducts. Similarly, concentrations of bile pigment became lower progressively with increasing injury to the gallbladder.

The writers were aided by George R. Kingsley and Hiram F. Snider, who assisted in tests of the accuracy of the procedure employed for cholesterol determination and who also performed most of the cholesterol analyses. We are also indebted to Doctors E. L. Eliason, I. S. Ravdin, G. P. Mueller and H. L. Owen for specimens.

\section{BIBLIOGRAPHY}

1. Lichtwitz, A., Prinzipien der Konkrementbildung (Bildung der Gallensteine und Harnsteine). Handbuch der Normalen und Pathologischen Physiologie, 1929, 4, 591.

2. Autenrieth, W., and Funk, A., Ueber kolorimetrische Bestimmungsmethoden: Die Bestimmung des Gesamtcholesterins im Blut und in Organen. München. med. Wchnschr., 1913, 60, 1243.

3. Quick, A. J., A continuous extractor. Ind. Eng. Chem., Analytical Edition, 1933, 5, 76.

4. Reinhold, J. G., and Wilson, D. W., The determination of cholic acid in bile. J. Biol. Chem., 1932, 96, 637.

5. Mathews, A. P., Physiological Chemistry. William Wood and Co., New York, 1930, 5th ed.

6. Reinhold, J. G., and Wilson, D. W., The acid-base composition of hepatic bile. I. Am. J. Physiol., 1934, 107, 378.

7. Sunderman, F. W., and Williams, P., Diminution in chloride measurement after drying blood and tissues. J. Biol. Chem., 1931, 92, 99.

8. Reinhold, J. G., and Ferguson, L. K., The reaction of human bile and its relation to gall stone formation. J. Exper. Med., 1929, 49, 681.

9. Ray, T. W., A microchemical study of human biliary calculi. J. Biol. Chem., 1935, 111, 689.

10. Johnston, C. G., Ravdin, I. S., Riegel, C., and Allison, C. L., Studies on gallbladder function. IX. The anion-cation content of bile from the normal and infected gallbladder. J. Clin. Invest., 1933, 12, 67.

11. Andrews, E., Detailed studies of a series of gallbladder cases. Surg., Gynec. and Obst., 1933, 57, 36.

12. Wieland, H., and Reverey, G., Untersuchungen über die Gallensäuren. XXI. Zur Kenntnis der menschlichen Galle. Ztschr. f. physiol. Chem., 1924, 140, 186.

13. Doubilet, H., Differential quantitative analysis of bile acids in bile and in duodenal drainage. J. Biol. Chem., 1936, 114, 289.

14. Fischer, H., Zur Kenntniss der Gallenfarbstoffe. I. Ztschr. f. physiol. Chem., 1911, 73, 204.

15. Greene, C. H., Walters, W., and Fredrickson, C. H., 
The composition of the bile following the relief of biliary obstruction. J. Clin. Invest., 1930, 9, 295.

16. Ravdin, I. S., Johnston, C. G., Riegel, C., and Wright, S. L., A study of human liver bile after release of common duct obstruction. J. Clin. Invest., 1933, 12, 659.

17. Breusch, F., and Johnston, C. G., Zum verschwinden und wiedererscheinen der Gallensäuren in der galle bei vorübergehendem choledochusverschluss. Klin. Wchnschr., 1934, 13, 1856.

18. Gilman, A., and Cowgill, G. R., Osmotic relations between blood and body fluids. IV. Pancreatic juice, bile and lymph. Am. J. Physiol., 1933, 104, 476.

19. Hammarsten, H., Untersuchungen einiger hochmolekularer Elektrolyte mit Hinsicht auf ihre Bedeutung in der Zelle. Biochem. Ztschr., 1924, 147, 481.

20. Okada, S., On the reaction of bile. J. Physiol., 1915, 50, 114.

21. Drury, D. R., McMaster, P. D., and Rous, P., Observations on some causes of gall stone formation. III. The relation of the reaction of the bile to experimental cholelithiasis. J. Exper. Med., 1924, 39, 403.

22. Peters, J. P., and Van Slyke, D. D., Quantitative Clinical Chemistry. Vol. I. Interpretations. Williams and Wilkins Co., Baltimore, 1931.

23. Sendroy, J., Jr., Seelig, S., and Van Slyke, D. D., Studies of acidosis. XXIII. The carbon dioxide tension and acid-base balance of human urine. $\mathrm{J}$. Biol. Chem., 1934, 106, 479.

24. deBeer, E. J., Johnston, C. G., and Wilson, D. W., The composition of intestinal secretions. J. Biol. Chem., 1935, 108, 113.

25. Aronsohn, H. G., and Andrews, E., Non-bacterial cholecystitis. The mechanism of acidification of bile in the gall bladder. Proc. Soc. Exper. Biol. and Med., 1935, 33, 89.

26. Hammarsten, O., Zur Chemie der Galle. Ergebn. d. Physiol., 1905, 4, 1.

27. Fischgold, H., and Chain, E., On the ampholytic nature of phospholipins. Proc. Roy. Soc. London, s. B., 1935, 117, 239.

28. Chain, E., and Kemp, I., The isoelectric points of lecithin and sphingomyelin. Biochem. J., 1934, 28, 2052.

29. Jukes, T. H., The electrometric titration of lecithin and cephalin. J. Biol. Chem., 1934, 107, 783.

30. Newman, C. E., Beitrag zum Studium der Gallenniederschlags- und Gallen-steinbildung. Beitr. z. path. Anat. u. z. allg. Path., 1931, 86, 187.

31. Andrews, E., Schoenheimer, R., and Hrdina, L., Etiology of gallstones. I. Chemical factors and the rôle of the gallbladder. Arch. Surg., 1932, 25, 796.

32. Wright, A., I. Cholesterol and cholesterol esters in dog bile. Quantitative methods. J. Exper. Med., 1934, 59, 407.
33. Riegel, C., Ravdin, I. S., Johnston, C. G., and Morrison, P. J., Studies of gall-bladder function. XII. The composition of "white bile." Am. J. M. Sc., 1935, 190, 655.

34. Ravdin, I. S., Johnston, C. G., Austin, J. H., and Riegel, C., Studies of gall-bladder function. IV. The absorption of chloride from the bile-free gallbladder. Am. J. Physiol., 1932, 99, 638.

35. Inouye, K., and Ryuichi, O., Experimental studies in gall-stone formation. Report I. Ber. u. d. ges. Physiol. u. exp. Pharmakol., 1930, 55, 716. Orig. from Jap. J. Gastroenterol., 1929, 1, 14.

36. Phemister, D. B., Day, L., and Hastings, A. B., Calcium carbonate gallstones and their experimental production. Ann. Surg., 1932, 96, 595.

37. Spanner, G. O., and Bauman, L., The behavior of cholesterol and other bile constituents in solutions of bile salts. J. Biol. Chem., 1932, 98, 181.

38. Fürth, O., and Scholl, R., Uber den Einfluss von gallensauren Salzen auf Diffusions- und Resorptionsvorgänge. Ein Beitrag zur Physiologie der Fettverdauung. Biochem. Ztschr., 1930, 222, 430.

Fürth, O., and Minibeck, H., Ǔber das Mengenverhältnis von Gallensäuren und Fetten im Darminhalte und dessen Beziehung zur Fettresorption. Ibid., 1031, 237, 139.

39. Riegel, C., Ravdin, I. S., and Johnston, C. G., Studies of gall-bladder function. VI. The absorption of bile salts and cholesterol from the bile-free gall bladder. Am. J. Physiol., 1932, 99, 656.

40. Ishii, Kenjiro, Antagonistic action of lipides to the toxic action of the bile salt. Sei-i-kwai Med. J., 1934, 53, 94-191. (English abst. 6-8.) Chem. Abstr., 1935, 29, 4086.

41. Andrews, E., Hrdina, L., and Dostal, L. E., Etiology of gallstones. II. Analysis of duct bile from diseased livers. Arch. Surg., 1932, 25, 1081.

42. Riegel, C., Ravdin, I. S., Morrison, P. J., and Potter, M. J., Studies of gallbladder function. XI. The composition of the gallbladder bile in pregnancy. J. A. M. A., 1935, 105, 1343.

43. Goff, M., Hrdina, L., and Andrews, E., Effect of prolonged stasis on the bile salt-cholesterol ratio. Proc. Soc. Exper. Biol. and Med., 1932, 29, 549.

44. McMaster, P. D., Broun, G. O., and Rous, P., Studies on the total bile. III. On the bile changes caused by a pressure obstacle to secretion; and on hydrohepatosis. J. Exper. Med., 1923, 37, 685.

45. Ivy, A. C., The physiology of the gall bladder. Physiol. Rev., 1935, 14, 1.

46. Weiser, H. B., and Gray, G. R., Mechanism of the formation of pure cholesterol gallstones. Arch. Path., 1934, 17, 1.

47. Riegel, C., Ravdin, I. S., Johnston, C. G., and Morrison, P. J., Studies of gall-bladder function. XIII. The composition of gall-bladder bile and calculi in gallbladder diseases. Surg. Gynec., and Obst., 1936, 62, 933. 
48. Brand, J., Beitrag zur Kenntniss der menschlichen Galle. Arch f. d. ges. Physiol., 1902, 90, 491.

49. Strauss, H. Cited by Ravdin et al. (16).

50. Graham, E. A., and Mackey, W. A., A consideration of the stoneless gallbladder. J. A. M. A., 1933, $103,1497$.
51. Kirklin, B. R., Necessity for accurate technique in oral cholecystography. Am. J. Roentgenol. and Rad. Ther., 1931, 25, 595.

52. Ravdin, I. S., Riegel, C., Johnston, C. G., and Morrison, P. J., Studies in biliary tract disease. J. A. M. A., 1933, 103, 1504. 